\title{
OBITUARY
}

\section{Gabriel Omar Skuk Sugliano (1962-2011)}

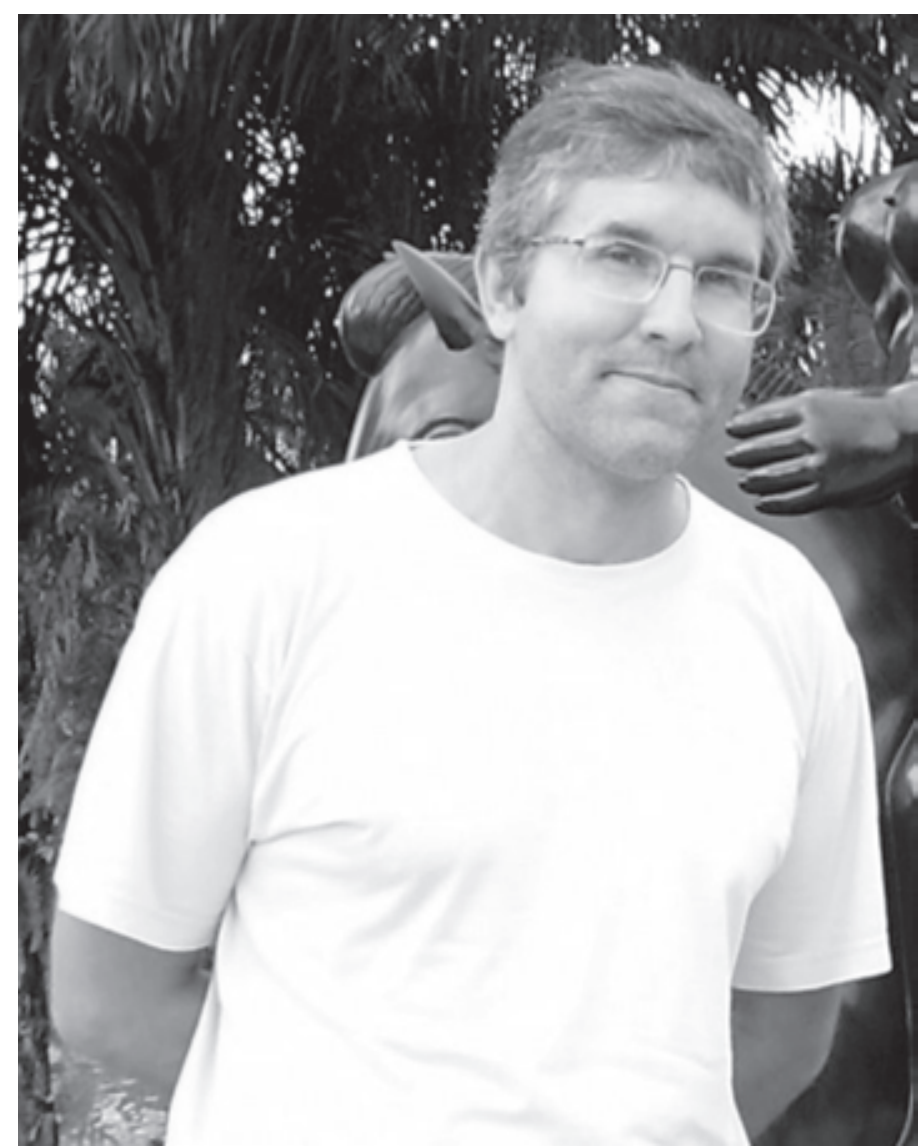

Gabriel Omar Skuk Sugliano, Salvador, BA, Brazil, May, 2008.

On 19 March, 2011, the herpetological community was shocked to learn of the death of Gabriel Omar Skuk Sugliano. Impassioned by the natural world, his life was interrupted at the early age of 49 years.

Gabo, as he was affectionately known, was born on 1 January, 1962 in Montevideo, Uruguay. He was the youngest son of Mario Andres Skuk and Marta Nirma Sugliano and began to show interest in Zoology from the age of nine, collecting beetles, butterflies and other insects. His passion for Herpetology was the result of a book entitled Anfibios y Reptiles del Uruguay, from which he learned basic notions of Morphology and Systematics and how to collect and fix specimens from this group. During this period he started a small private collection, which was later donated to the Museu de Zoologia, Universidade de São Paulo (São Paulo, Brazil). On a visit to the Museo de Historia Natural of Montevideo, he was given a guided tour of the facility by Dr.
Orejas-Miranda. According to Gabriel, this visit played a decisive role in his choice of a scientific career.

At the age of 12, he entered the Centro de Estudios de Ciencias Naturales, Montevideo, for students of Biology and Archeology. The center promoted conferences and field trips and maintained a Zoology laboratory for basic level students directed by Blegini, a layman devoted to the area. Gabriel was responsible for reptiles, while his friend Rafael de Sá, currently a professor at the University of Richmond, (USA), was in charge of amphibians. In his seven years with the group he traveled throughout Uruguay, collecting zoological specimens and participating in archeological research.

In 1980, he enrolled in the Facultad de Humanidades y Ciencias at the Universidad de Uruguay (today Facultad de Ciencias) in order to study Biological Sciences. During that year, he made his first study-related trip to Brazil, taking part in Bio- 
logical Debates in Porto Alegre, Rio Grande do Sul, where he gave a short presentation on the Teiidae of Uruguay. He also established friendships with Brazilian students, several of whom are today renowned university researchers. In 1982 he was invited to participate in the IX Brazilian Congress of Zoology, also in Porto Alegre. From then onwards he often visited Brazil to take part in expeditions across country.

From the outset he demonstrated immense intellectual curiosity, becoming interested in Evolutionary Biology after reading the works of Ernst Mayr and Theodosius Dobzhansky. In 1984, while still an undergraduate, this interest led to a formal relationship with the Universidad de Uruguay as an "honorary collaborator", lecturing in the Department of Genetics and conducting research into the cytogenetics of amphibians and reptiles.

In 1986, he was hired by the Department of Vertebrates, where he taught undergraduates, collected vertebrates in the field and continued his studies in cytogenetics. In 1988, he was offered the opportunity of traveling to the Galapagos Islands by, the Charles Darwin Scientific Station, where he participated in an international symposium responsible for developing, reptile management and conservation plans for the archipelago. During this period, he also carried out collections in the Andes and Napo River region of the Amazon.

At the suggestion of Dr. Alfredo Langguth, a specialist in mammals at the Universidade Federal da Paraíba (UFPB), in 1987 Gabriel asked Dr. Miguel Trefault Rodrigues from the Zoology Department at the Universidade de São Paulo (USP) to be his postgraduate advisor. Two years later he enrolled in the Masters Zoology Program at the USP Bioscience Institute, where he defended his dissertation entitled "Geographic variation, ecology and phylogenetic relationships in the Tropidurus nanuzae species group". In 1991, while still in the Masters Program, he met his future wife and lifelong companion, Beatriz Fabiana Baldas.

He enrolled in the Doctoral Program at the same institution in 1994, once again under professor Rodrigues and defended his thesis entitled "Review of lizards from the Ameiva ameiva complex (Squamata: Teiidae)". His patience and discerning "clinical eye" combined, with his ingenuity in creating tools made him an excellent collector, drawing admiration and praise from his colleagues. During his doctorate he developed studies on the cytogenetics of amphibians and reptiles in collaboration with the Department of Biology at USP. Gabriel became a close friend of Miguel Trefault Rodrigues, evidenced in the admiration and affection with which he referred to his former advisor in conversations with friends and students. His two sons, Breno Baldas Skuk and Enzo Baldas Skuk, were born in 1996 and 1999, respectively. At the end of the year 2000, he was invited by the Department of Systematics and Ecology at the Universidade Federal da Paraíba (UFPB), João Pessoa, as a visiting researcher associated to the project entitled "Study of Biodiversity in the Barra do Rio Mamanguape Environmental Protection Area", part of the Northeast Program for Research and Postgraduate Work sponsored by the CNPq (National Research Council). During this time he also investigated herpetofauna diversity in the area, began to reorganize the herpetological collection at UFPB and advise undergraduate students. Between 2001 and 2002 Gabriel developed research activities as a Regional Scientific Development scholarship holder, taking part in projects entitled "Study of reptile fauna in the humid highland forests of Northeast Brazil" and "Study of phylogenetic relationships in species from Kentropyx (Squamata: Teiidae)".

In 2002, he passed a public service exam and was approved for the position of adjunct professor in the former Department of Zoology at the Centro de Ciências Biológicas, Universidade Federal de Alagoas (UFAL), Maceió, where he delighted everyone with his undeniable intellectual capacity and willingness to help others. A few years after assuming the post of professor, he was named head of the department and curator of the herpetological collection of the Museu de História Natural at the same institution. Without abandoning reptiles, but aware of the lack of research on amphibian fauna in Alagoas, Gabriel decided to focus his studies on this group. In conjunction with several students, he developed a project entitled "Study of anuran amphibians in the Eastern Atlantic Forest: fauna of the coastal tablelands of Alagoas". This marked the group's first study in the state, resulting in a number of subsequent investigations.

His classes always contained the most interesting and updated content and he often said that teaching was one of his preferred activities in academia. Gabriel advised several students at UFAL, always willing to help them in any way he could and encouraging them to pursue their studies by lending them books from his library, giving extra classes or arranging contacts with researchers at other institutions.

In daily academic practice, his skills as a scientific artist and photographer also stood out, leading to several awards and the publication of his photographs in a number of articles and books. Always enthusiastic, he was often seen teaching students and colleagues some of his techniques and secrets in these areas.

We are left with fond memories and the privilege of having known this simple, captivating figure who loved his work. His example will never be forgotten.

\title{
Filipe A. Nascimento ${ }^{1,2}$; Bruno Vilela ${ }^{1,2} \&$ Barnagleison Lisboa ${ }^{1}$
}

\author{
1 Setor de Zoologia, Museu de História Natural, Universidade Federal de Alagoas. Avenida Aristeu de Andrade, Farol, \\ 57051-090 Maceió, AL, Brazil. E-mail: filipe.bio@gmail.com \\ 2 Programa de Pós-Graduação em Diversidade Biológica e Conservação nos Trópicos, Instituto de Ciências Biológicas e da \\ Saúde, Universidade Federal de Alagoas. Praça Afrânio Jorge, Prado, 57010-020 Maceió, AL, Brazil.
}

